\title{
Equivalent Carbon Dioxide Emission in Useful Energy Generation in the Heat-Generating Plant - Application of the Carbon Footprint Methodology
}

\author{
Zdzisław Chłopek', Jakub Lasocki ${ }^{1 *}$, Krzysztof Melka², Krystian Szczepański \\ 1 Warsaw University of Technology, Faculty of Automotive and Construction Machinery Engineering, \\ Narbutta 84, 02-524 Warszawa, Poland \\ 2 Institute of Environmental Protection - National Research Institute, Krucza 5/11D, 00-548 Warszawa, Poland \\ * Corresponding author's e-mail: jakub.lasocki@pw.edu.pl
}

\begin{abstract}
The energy sector worldwide is a significant source of air pollutant emission. In Poland, the vast majority of heat and electricity is generated in coal-fired heat and power plants. There is a common belief that high greenhouse gas emissions from the energy sector in Poland are mainly due to the technological processes involving the conversion of energy by burning fossil fuels. However, coal mining also causes a high environmental burden. This paper aimed to determine the carbon footprint of a typical hard coal-fired heating plant in Poland, taking into account mining of hard coal, its transport to the heating plant and useful energy generation in the heating plant. The investigation carried out allowed comparing the process steps and determining which of them is the dominant source of the greenhouse gas emissions. The obtained results show that hard coal mining and hard coal transport account for almost $65 \%$ and $5 \%$ of total equivalent carbon dioxide emission, respectively. Energy transformations in the heating plant account for $30 \%$ of total equivalent carbon dioxide emission, where approx. $29 \%$ is due to hard coal burning and $1 \%$ due to electricity consumption. The relative shares of carbon dioxide, methane and nitrous oxide in total equivalent carbon dioxide emission account for approx. $91 \%, 4 \%$ and $5 \%$, respectively.
\end{abstract}

Keywords: carbon dioxide $\left(\mathrm{CO}_{2}\right)$, greenhouse gases (GHG), emission, energy generation, heat plant, coal, carbon footprint $(\mathrm{CF})$

\section{INTRODUCTION}

The carbon footprint $(\mathrm{CF})$ can be used in the analyses on environmental impacts. It is examined in order to quantify the potential influence of the object of study on intensification of the greenhouse effect, and consequently - on climate change. The carbon footprint is the total greenhouse gas (GHG) emissions caused by the object of interest. The procedure for CF calculation corresponds to that used to determine total greenhouse gas emissions in the Life Cycle Assessment (LCA), and can be regarded as a detailed approach to LCA, focused on the "climate change" impact category [BSI 2011].

The greenhouse effect is the process of warming of the Earth's surface and troposphere, as a result of a limited radiation transfer from the Earth's surface and the atmosphere directly into space. The effect is aggravated by the presence of greenhouse gases with polyatomic molecules in the atmosphere. In contrast to the mono- or diatomic gases, the greenhouse gases absorb low frequency radiation emitted by warmed Earth's surface more intensively than high frequency solar radiation. In this way, solar radiation reaches the Earth's surface, while the Earth's radiation is largely absorbed by the atmosphere and re-emitted in all directions, including back to the Earth's surface [Myhre et al. 2013].

The most important gases that directly contribute to the greenhouse effect include [Myhre et al. 2013]:

- water $\left(\mathrm{H}_{2} \mathrm{O}\right)$, 
- carbon dioxide $\left(\mathrm{CO}_{2}\right)$,

- methane $\left(\mathrm{CH}_{4}\right)$

- nitrous oxide $\left(\mathrm{N}_{2} \mathrm{O}\right)$,

- hydrofluorocarbons (HFC),

- perfluorinated compounds:

- sulfur hexafluoride $\left(\mathrm{SF}_{6}\right)$,

- nitrogen trifluoride $\left(\mathrm{NF}_{3}\right)$,

- perfluorocarbons (PFCs),

- fluorinated ethers (HFE),

- perfluoropolyethers (PFPE),

- chlorofluorocarbons (CFCs),

- hydrochlorofluorocarbons (HCFC).

Water in a gaseous state (water vapor) is the most important for the greenhouse effect and plays an essential role in shaping the Earth's climate. The amount of water vapor in the atmosphere is in direct relation to the temperature. Natural processes, such as ocean, sea and inland water evaporation, as well as plant transpiration, contribute to the water vapor emission to the atmosphere. The anthropogenic sources, such as e.g. evaporation of the water used for irrigation of crops or cooling of power plants, have no significant influence on the greenhouse effect, and consequently - on the global climate. Therefore, water vapor is not included in the inventory of the greenhouse gas emissions associated with human activities.

The methodology for CF calculation includes the assessment of the greenhouse gas emissions all the way through explicit lifetime of the examined object, taking into account direct and indirect emissions, as well as potential emissions, i.e. those avoided due to the existence of the tested object. Each greenhouse gas emission is expressed as equivalent carbon dioxide emission $\left(\mathrm{CO}_{2 \mathrm{eg}}\right)$ and the sum of equivalent carbon dioxide emissions values is referred to the functional unit (an element also used in LCA). The carbon footprint is expressed in the emission unit (gram) per the functional unit.
Consistent with the methodology proposed by IPCC [Myhre et al. 2013, IPCC 2006, Houghton et al. 2001], equivalent carbon dioxide emission is obtained by multiplying the emission of a given greenhouse gas by its Global Warming Potential (GWP) for the given time horizon. The GWP value depends on the properties of a greenhouse gas as regards the absorption of electromagnetic radiation and the time period of its remaining in the atmosphere. Usually, GWP refers to the time horizon of 20, 100 or 500 years (the longer the considered period, the greater the error of the GWP value). In many published studies and reports prepared for decision makers, the standard 100-year time horizon is assumed [Myhre et al. 2013]. Regardless the time period used, the GWP value of carbon dioxide is 1 , as it is the gas used as the reference. As science and technology advance, new findings are included in IPCC analyses, and consequently, the revised GWP values are presented in subsequent reports. The examples of the GWP values, taken from the Fifth IPCC Report (2013) [Myhre et al. 2013], are presented in Table 1.

$\mathrm{CF}$ calculation comprises a complex procedure, which requires defining the boundaries of the system tested, gathering the relevant quantitative data and accurately interpreting the results obtained. Taking an arbitrary decision, as it is done in LCA, can negatively affect the reliability, verifiability and comparability of CF calculations. Even small differences between the methodologies used in calculations can lead to obtaining different CF values for the same study object. This is confirmed by the existing comparative studies, e.g. regarding biofuels [Whittaker et al. 2011] and other products [Dias and Arroja 2012, Garcia and Freire 2014, Pattara et al. 2016, Soode et al. 2013, Wang et al. 2018, Peter et al. 2016], which allow identifying key aspects of the methodology that can lead to the result discrepancies. These include: defining the system boundaries, adopting the cut-off criteria, taking into account (or not)

Table 1. Global warming potentials (GWP) of selected greenhouse gases [Myhre et al. 2013]

\begin{tabular}{|l|c|c|c|}
\hline \multicolumn{1}{|c|}{ Name } & Chemical formula & GWP $_{20}$ & $\begin{array}{c}\mathrm{GWP}_{100} \\
\text { (20 years horizon) }\end{array}$ \\
\hline Carbon dioxide & $\mathrm{CO}_{2}$ & 1 & 1 \\
\hline Methane & $\mathrm{CH}_{4}$ & 84 & 28 \\
\hline Nitrous oxide & $\mathrm{N}_{2} \mathrm{O}$ & 264 & 265 \\
\hline Sulfur hexafluoride & $\mathrm{SF}_{6}$ & 17,500 & 23,500 \\
\hline Carbon tetrachloride & $\mathrm{CF}_{4}$ & 4880 & 6630 \\
\hline Trichlorofluoromethane (CFC-11, freon-11) & $\mathrm{CCl}_{3} \mathrm{~F}$ & 6900 & 4660 \\
\hline
\end{tabular}


non-fossil carbon dioxide emission, emission allocation rules, and the like [Wang et al. 2018].

The standard methodology for CF calculation was developed and published in the normative documents. The choice of methodology depends on the study object. For a single object, 'Product Carbon Footprint' guidelines are used, and in the case of the whole organization (e.g. an enterprise) - 'Corporate Carbon Footprinting' guidelines. The overall methodology always stays the same; however, detailed assumptions may be different.

The most commonly used international normative documents on the carbon footprint, are:

- 'Publicly Available Specification 2050' (PAS 2050) [2011] - the guidelines developed by the British Standards Institute (BSI) in 2008, revised in 2011;

- 'GHG Protocol Product Standard' [2011] - the guidelines developed by the World Resources Institute (WRI), in cooperation with the World Business Council for Sustainable Development (WBCSD), in 2011;

- ISO 14067. Greenhouse gases - Carbon footprint of products - Requirements and guidelines for quantification [2018] - the standard developed by the International Organization for Standardization (ISO), based on the existing LCA standards, published in 2013.

PAS 2050 was published first, and then 'GHG Protocol Product Standard' was elaborated based on the methodology developed in PAS 2050. Later, PAS 2050 was revised consistently with 'GHG Protocol Product Standard'. Both documents provide comprehensive guidelines and allow for unambiguous result interpretations. The ISO 14067 carbon footprint standard was published afterwards and is perceived as relatively general; however, some of the provisions of this document are quite precise, e.g. in the case of the guiding principles for quantification of electricity from renewable sources. The basic assumptions of the methodology presented in the three abovementioned documents are the same and based on the existing requirements in the Life Cycle approach, established in the ISO 14040 [2006] and ISO 14044 [2006] standards. Nonetheless, the detailed solutions provided in the aforesaid documents slightly differ from each other, even though the institutions involved in their development (BSI, WRI/WBCSD and ISO) collaborated during preparation/revision of the documents.
In addition to the international initiatives, the actions to develop a consistent methodology for CF calculations have been undertaken at a national or local level, by public or private organizations. The proposed solutions focus on the greenhouse gas emissions alone or include other types of environmental impacts. For instance, the 'EcoLeaf Environmental Labeling' program has been developed and implemented in Japan [SMPO 2020], and in France, a methodological approach 'French Environmental Footprint BP X30-323' [ADEME 2009] has been developed. Comprehensive evaluation of the approaches used in the normative documents is available in subject literature [Soode et al. 2013, Wang et al. 2018, JRC 2011, Schmied and Knörr 2012].

The use of the methodology for assessing the greenhouse gas emissions in the energy sector has been discussed in several published works. The study [WRI/WBCSD 2006] refers to the methodology recommended in the assessment of the greenhouse gas emissions in energy projects. In [EIB 2020], attention is drawn to the necessity of employing the holistic view to the assessment criteria for the projects in the energy sector, taking into account the economic effect. It is also important to note that the methodology for CF calculations is not as universal as that for LCA.

In the study [De Souza et al. 2018], two methods of electricity supply to the heat pump were compared, i.e. from the national electricity network (the Brazilian electricity mix) and from the solar photovoltaic system. The results obtained showed the prospects to significantly reduce the carbon footprint, in consequence of the use of energy from the photovoltaic system.

Motivating views on the effectiveness of the use of renewable energy in energy projects, based on New Zealand's solutions, were presented in the study [Atkins et al. 2017]. On the other hand, as the authors stated, considerable reduction in the greenhouse gas emissions was in many cases outweighed by high costs of renewable energy.

The study [Aghahosseini et al. 2019] showed the results related to the effectiveness of using renewable energy in the energy sector, in view of the greenhouse gas emissions in the perspective of 2030. Substantial differences in the effectiveness of the use of renewable energy sources were observed, depending on the centralization of the renewable energy supply system.

The greenhouse gas emissions from a coalfired heating plant were considered in the study 
[Gai et al. 2018]. The discussed results indicated that the structures of greenhouse gas emissions might differ notably, depending on the technical solutions applied.

In the study [Agrawal et al. 2014], the Life Cycle approach was used to assess the greenhouse gas emissions and their impacts due to the combined cycle of natural gas and imported coal in a heating plant. IPCC 2001 and Eco-Indicator 99 methods were used for the analysis. Significant ecological benefits were observed due to the use of natural gas. Analogous results were presented in the study [Gonzalez-Salazar et al. 2018], carried out with the aim to compare the effects of hard coal and natural gas utilized in the energy system with the use of different technologies.

This paper aimed to determine the carbon footprint of a typical hard coal-fired heating plant in Poland, taking into account coal mining, coal transport to the heating plant and useful energy generation in the heating plant. The investigation carried out allowed comparing process steps and determining which of them is the dominant source of the greenhouse gas emissions.

\section{METHODOLOGY}

The cumulative processes were adopted as the system boundaries in the methodology used for the calculation of equivalent carbon dioxide emission in generation of the useful energy in the coal-fired heating plant:

- hard coal mining - M,

- transport of hard coal to the heating plant - T,

- energy transformations in the heating plant $-\mathrm{H}$.

The considered cumulative processes consist of elementary processes, and are the most important in the functioning of the coal-fired heating plant as regards the greenhouse gas emission.

For the processes examined, the following greenhouse gases were considered:

- hard coal mining: carbon dioxide $\left(\mathrm{CO}_{2}\right)$ and methane $\left(\mathrm{CH}_{4}\right)$,

- transport of hard coal to the heating plant: carbon dioxide $\left(\mathrm{CO}_{2}\right)$, methane $\left(\mathrm{CH}_{4}\right)$, and nitrous oxide $\left(\mathrm{N}_{2} \mathrm{O}\right)$,

- useful energy generation in the heating plant: carbon dioxide $\left(\mathrm{CO}_{2}\right)$.

Annual equivalent carbon dioxide emission $\left(\mathrm{E}_{\mathrm{CO} 2 \mathrm{eq}}\right)$ from the coal-fired heating plant amounts to:

$$
\mathrm{E}_{\mathrm{CO2eq}}=\mathrm{E}_{\mathrm{CO2eq-} \mathrm{M}}+\mathrm{E}_{\mathrm{CO} 2 \mathrm{eq}-\mathrm{T}}+\mathrm{E}_{\mathrm{CO} 2 \mathrm{eq}-\mathrm{H}},
$$

where: $E_{\text {CO2eq-M }}$ - equivalent carbon dioxide emission in the process of hard coal mining, $E_{\text {CO2eq-T }}$ - equivalent carbon dioxide emission in the process of hard coal transport $\mathrm{f}$ to the heating plant

$E_{\text {COZeq-H }}$ - equivalent carbon dioxide emission in the process of useful energy generation in the heating plant.

Equivalent carbon dioxide emission from each of the processes " $\mathrm{X}$ " $\left(\mathrm{E}_{\mathrm{CO} \text { eq }-\mathrm{X}}\right)$ is the sum:

$$
=\mathrm{E}_{\mathrm{CO} 2 \text { eq-X-CO2 }}+\mathrm{E}_{\mathrm{CO} 2 \text { eq-X }-\mathrm{X}-\mathrm{X}-\mathrm{CH} 4}=
$$

where: $\mathrm{E}_{\mathrm{CO} 2 e q-\mathrm{X}-\mathrm{CO} 2}-$ carbon dioxide emission in the process " $X$ ",

$\mathrm{E}_{\mathrm{CO2eq-X-CH4}}-$ methane emission in the process " $\mathrm{X}$ ",

$\mathrm{E}_{\mathrm{CO2eq}-\mathrm{X}-\mathrm{N} 2 \mathrm{O}}-$ nitrous oxide emission in the process " $\mathrm{X}$ ".

Equivalent carbon dioxide emission for substance " $Y$ " in the process " $\mathrm{X}$ " is:

$$
\mathrm{E}_{\mathrm{C} 02 \mathrm{eq}-\mathrm{X}-\mathrm{Y}}=\mathrm{E}_{\mathrm{X}-\mathrm{Y}} \cdot \mathrm{GWP} 100_{\mathrm{Y}} \text {, }
$$

where: $E_{X-Y}-$ " $Y$ " substance emission in the process " $X$ ",

$G W P 100_{Y}$ - global warming potential of "Y" substance in the 100-year time horizon.

Emission of substance " $\mathrm{Y}$ " in the process " $\mathrm{X}$ " is calculated as the product:

$$
\mathrm{E}_{\mathrm{X}-\mathrm{Y}}=\mathrm{EN}_{\mathrm{X}} \cdot \mathrm{WE}_{\mathrm{X}-\mathrm{Y}},
$$

where: $E N_{X}$ - energy consumption in process "X",

$W E_{X-Y}-$ emission factor for substance "Y" in process " $\mathrm{X}$ ".

For road transport, emission of substance " $Y$ " can be alternatively calculated as the product:

$$
\mathrm{E}_{\mathrm{T}-\mathrm{Y}}=\mathrm{L} \cdot \mathrm{b}_{\mathrm{Y}},
$$

where: $L-$ the total distance travelled by a means of transport to deliver hard coal to the heating plant,

$b_{Y}$ - average specific distance emission of substance "Y" from a means of transport of hard coal to the heating plant.

Specific distance emission from road transport of substance " $\mathrm{Y}$ " $\left(\mathrm{b}_{\mathrm{Y}}\right)$ is derived from emission of substance " $\mathrm{Y}$ " from road vehicle $\left(\mathrm{m}_{\mathrm{Y}}\right)$ in relation to distance (s) travelled by this vehicle: 


$$
\mathrm{b}_{\mathrm{Y}}=\frac{\mathrm{dm}_{\mathrm{Y}}}{\mathrm{ds}}
$$

The most important difficulties in equivalent carbon dioxide emission calculation for the emissions associated with useful energy generation in the coal-fired heating plant, are related to the calculations of:

- emission energy factor for the greenhouse gases in the cumulative processes examined,

- average greenhouse gas specific distance emission from road transport vehicles.

The emission energy factor for the cumulative processes under study was determined based on the emission energy factors calculated for the elementary processes as components of the cumulative processes examined. The average emission of a given greenhouse gas from road transport was expressed by the quotient of the greenhouse gas emission from all road vehicles transporting hard coal to the heating plant and the total distance traveled by these fuels in the transport to heating plants. In practice, calculation of the average emission of specific substances from road transport is most often simplified by using inventory databases for pollutants from road transport, in reference to the 2006 IPCC Guidelines for National Greenhouse Gas Inventories [IPCC 2006] and EEA/EMEP Emission Inventory Guidebook 2019 [EEA/EMEP 2019].

\section{CALCULATION RESULTS}

The calculation of carbon dioxide equivalent emission was developed for the heating plant that annually used:

- $22.2 \mathrm{Gg}$ of hard coal,

- $6.120 \mathrm{TJ}$ of electricity.

The data on elementary processes were used for the calculation of the carbon dioxide emission energy factor in the process of hard coal mining, consistent with the data on fuel and energy consumption in hard coal mining in 2018, provided by Statistics Poland (formerly: Central Statistical Office, GUS) G-03 [2018] and carbon dioxide emission energy factors developed by KOBiZE [2019] and IPCC guidelines [2006] - Table 2.

The carbon dioxide emission factor in the process of hard coal mining can be calculated in line with the equation below:

$$
\mathrm{WE}_{\mathrm{M}-\mathrm{CO} 2}=\left(\sum_{\mathrm{i}} \mathrm{WE}_{\mathrm{Mi}-\mathrm{CO} 2} \cdot \mathrm{EN}_{\mathrm{Mi}}\right) / \sum_{\mathrm{i}} \mathrm{EN}_{\mathrm{Mi}}
$$

where: $W E_{\mathrm{Mi}-\mathrm{CO} 2}-$ carbon dioxide emission factor in the elementary process " $i$ " in the cumulative process of hard coal mining, $E N_{M i}$ - energy consumption in the elementary process " $i$ " in the cumulative process of hard coal mining.

The carbon dioxide emission factor in the hard coal mining process calculated with the use of the equation (7) amounts to $188.82 \mathrm{~kg} / \mathrm{GJ}$. The

Table 2. Energy consumption, carbon dioxide emission and energy factor for carbon dioxide emission in the elementary processes of hard coal mining in Poland in 2018

\begin{tabular}{|l|c|c|c|}
\hline \multicolumn{1}{|c|}{ Energy carrier } & $\begin{array}{c}\text { Energy consumption } \\
{[\mathrm{GJ}]}\end{array}$ & $\begin{array}{c}\text { Carbon dioxide emission } \\
{[\mathrm{Mg}]}\end{array}$ & $\begin{array}{c}\text { Carbon dioxide emission } \\
\text { energy factor [kg/GJ] }\end{array}$ \\
\hline Liquefied petroleum gas - LPG & 287 & 18 & 63.10 \\
\hline Lubricating and waste oils, used up & 605 & 44 & 73.30 \\
\hline Energy efficient hard coal & 488745 & 46665 & 95.48 \\
\hline Coke and semi-coke of coal & 422 & 34394 & 107.00 \\
\hline Diesel oils for combustion engines & 464162 & 5150 & 74.10 \\
\hline Engine and lubricating oils & 70253 & 37 & 73.30 \\
\hline Petroleum jelly, paraffin waxes, and the like & 509 & 16 & 73.30 \\
\hline Other kerosene & 224 & 53 & 73.30 \\
\hline Petroleum spirit and other special spirits & 729 & 168 & 73.30 \\
\hline Other petroleum products & 2295 & 75 & 69.30 \\
\hline Motor gasoline & 1087 & 0 & 0.00 \\
\hline Solid biofuels & 32686 & 214867 & 103.00 \\
\hline Steam and hot water energy & 2086092 & 2628808 & 212.50 \\
\hline Electricity & 12370860 & 2930343 & 188.82 \\
\hline Overall & 15518956 & & \\
\hline
\end{tabular}


methane emission factor in the hard coal mining process was assumed $0.331 \mathrm{~kg} / \mathrm{GJ}$ based on IPCC [2006]. Consistent with KOBiZE [2019], the carbon dioxide emission factor amounted to

Table 3. Hard coal transport to the heating plant

\begin{tabular}{|l|c|c|}
\hline \multicolumn{1}{|c|}{ Parameter } & Unit & Value \\
\hline Distance covered in one trip & $\mathrm{km}$ & 400 \\
\hline Number of trips & - & 888 \\
\hline Truck load capacity & $\mathrm{Mg}$ & 25 \\
\hline
\end{tabular}

$212.5 \mathrm{~kg} / \mathrm{GJ}$ for electricity generation. The parameters assumed for hard coal transport to the heating plant are presented in Table 3 .

Table 4 summarizes the data and results from the assessment of carbon dioxide equivalent emission in the production of useful energy in the coal-fired heating plant. The carbon dioxide energy factor values were obtained from the studies carried out by KOBiZE [2017, 2019].

Energy consumption by road transport trucks and average emissions of carbon dioxide, methane

Table 4. Data and results used in the assessment of carbon dioxide equivalent emission in generation of useful energy in a coal-fired heating plant

\begin{tabular}{|c|c|c|}
\hline Assessed processes and factors & Unit & Value \\
\hline Hard coal consumption in the heating plant & [Gg] & 22.2 \\
\hline Consumption of energy from hard coal burned in the heating plant & [TJ] & 486.40 \\
\hline Consumption of electricity in the heating plant & {$[\mathrm{TJ}]$} & 6.12 \\
\hline Specific energy consumption in hard coal mining & - & 0.00963 \\
\hline Energy consumption in hard coal mining for the heating plant & [TJ] & 4.682 \\
\hline Carbon dioxide emission factor in the process of hard coal mining & [kg/GJ] & 188.82 \\
\hline Carbon dioxide emission in the process of hard coal mining & [Gg] & 91.84 \\
\hline Methane emission factor in the process of hard coal mining & {$[\mathrm{kg} / \mathrm{GJ}]$} & 0.4427 \\
\hline Methane emission in the process of hard coal mining & {$[\mathrm{Gg}]$} & 0.2153 \\
\hline Carbon dioxide equivalent emission in the process of hard coal mining & {$[\mathrm{Gg}]$} & 102.62 \\
\hline Carbon dioxide emission factor for coal burned in the heating plant & {$[\mathrm{kg} / \mathrm{GJ}]$} & 94.9 \\
\hline Carbon dioxide emission from hard coal burned in a heating plant & {$[\mathrm{Gg}]$} & 46.16 \\
\hline Carbon dioxide equivalent emission from hard coal burned in the heating plant & {$[\mathrm{Gg}]$} & 46.16 \\
\hline Carbon dioxide emission factor for electricity generation for consumption by the heating plant & [kg/GJ] & 212.5 \\
\hline Carbon dioxide emission from electricity consumed by the heating plant & [Gg] & 1.30 \\
\hline Carbon dioxide equivalent emission from electricity consumed by a heating plant & {$[\mathrm{Gg}]$} & 1.30 \\
\hline Carbon dioxide emission from the heating plant & [GJ] & 47.46 \\
\hline Carbon dioxide equivalent emission for the heating plant & [GJ] & 47.46 \\
\hline Distance travelled by trucks & {$[\mathrm{km}]$} & 355200 \\
\hline Energy consumption in road transport & {$[\mathrm{MJ} / \mathrm{km}]$} & 9.0 \\
\hline Energy consumption in road transport of hard coal to the heating plant & [TJ] & 3.192 \\
\hline Specific distance emission of carbon dioxide from road transport of hard coal to the heating plant & {$[\mathrm{g} / \mathrm{km}]$} & 584 \\
\hline Carbon dioxide emission from road transport of hard coal to the heating plant & {$[\mathrm{Gg}]$} & 0.2076 \\
\hline Specific distance emission of methane from road transport of hard coal to the heating plant & {$[\mathrm{g} / \mathrm{km}]$} & 0.0007 \\
\hline Methane emission from road transport of hard coal to the heating plant & [Gg] & 0.00155 \\
\hline Specific distance emission of nitrous oxide from road transport of hard coal to the heating plant & {$[\mathrm{g} / \mathrm{km}]$} & 0.0255 \\
\hline Nitrous oxide emission from road transport of hard coal to the heating plant & {$[\mathrm{Gg}]$} & 0.0301 \\
\hline Equivalent carbon dioxide emission from road transport of hard coal to the heating plant & [Gg] & 8.2195 \\
\hline Carbon dioxide emission from the process of useful energy generation in the heating plant & [Gg] & 144.26 \\
\hline Methane emission from useful energy generation of in the heating plant & {$[\mathrm{Gg}]$} & 0.2169 \\
\hline Nitrous oxide emission from the process of useful energy generation in the heating plant & {$[\mathrm{Gg}]$} & 0.0301 \\
\hline Energy consumption in the process of useful energy generation in the heating plant & [TJ] & 500.40 \\
\hline Equivalent carbon dioxide emission in the process of generation of useful energy in the heating plant & {$[\mathrm{Gg}]$} & 158.302 \\
\hline Carbon dioxide emission factor in the process of useful energy generation in the heating plant & [kg/GJ] & 288.29 \\
\hline Methane emission factor in the process of useful energy generation in the heating plant & [kg/GJ] & 0.4334 \\
\hline Nitrous oxide emission factor in the process of useful energy generation in the heating plant & [kg/GJ] & 0.0601 \\
\hline $\begin{array}{l}\text { Equivalent carbon dioxide emission factor in the process of useful energy generation in the } \\
\text { heating plant }\end{array}$ & {$[\mathrm{kg} / \mathrm{GJ}]$} & 316.353 \\
\hline
\end{tabular}


and nitrous oxide from road transport were calculated based on INFRAS AG software data [INFRAS AG 2010] on traffic conditions equivalent to an average speed of approximately $70 \mathrm{~km} / \mathrm{h}$ for maximum mass road vehicles $(22 \div 34) \mathrm{Mg}$, with defined European emission standard Euro III $\div$ Euro VI. Figure 1 shows equivalent carbon dioxide emission from the cumulative processes of useful energy generation in the heating plant. Hard coal mining and hard coal transport account for almost $65 \%$ and $5.2 \%$ of total equivalent carbon dioxide emission, respectively. Energy transformations in the heating plant account for $30 \%$ of total equivalent carbon dioxide emission (29.2\% - from hard coal burning and approx. $0.82 \%$ from electricity consumption - Figure 2 ).

In terms of energy transformations in the heating plant, the greenhouse gas emission from hard coal burning is considerably higher when compared to that from electricity consumption. Figures 3-5 depict the carbon dioxide, methane and nitrous oxide emissions from the cumulative processes of useful energy generation of in the heating plant.

Obviously, the highest carbon dioxide emission results, at the outset, from hard coal mining and then from hard coal burning. The methane emission is almost exclusively associated with hard coal mining, whereas nitrous oxide emission is almost exclusively associated with hard coal transport to the heating plant. Figure 6 shows the greenhouse gas emission in the process of useful energy generation in the heating plant and the relevant equivalent carbon dioxide emission values.

The relative shares of methane and nitrous oxide in total equivalent carbon dioxide emission account for $3.84 \%$ and $5.03 \%$, respectively. The results of the present study show that in the

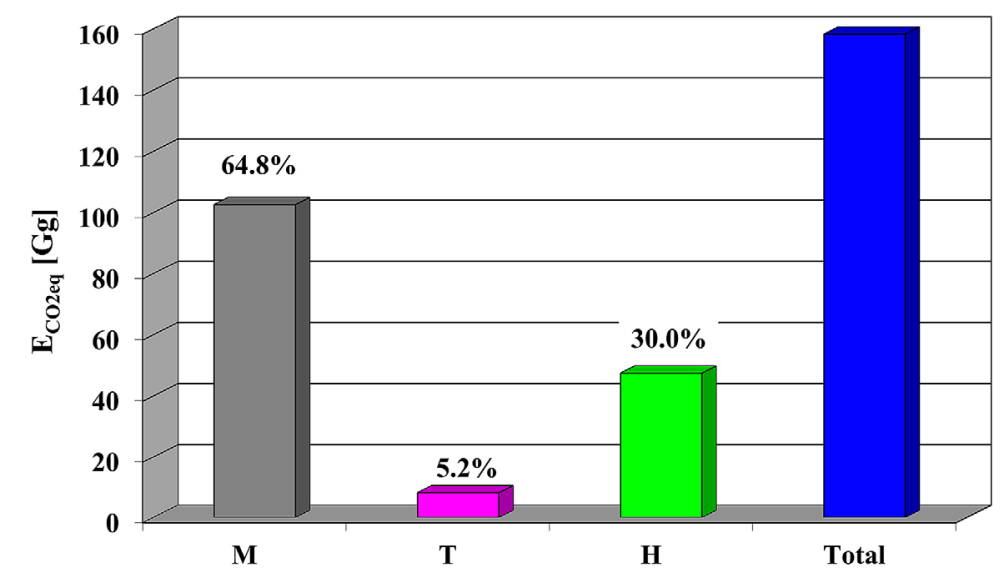

Figure 1. Equivalent carbon dioxide emission from the cumulative processes of useful energy generation in the heating plant: hard coal mining $-\mathrm{M}$, hard coal transport $-\mathrm{T}$, energy transformations in the heating plant $-\mathrm{H}$

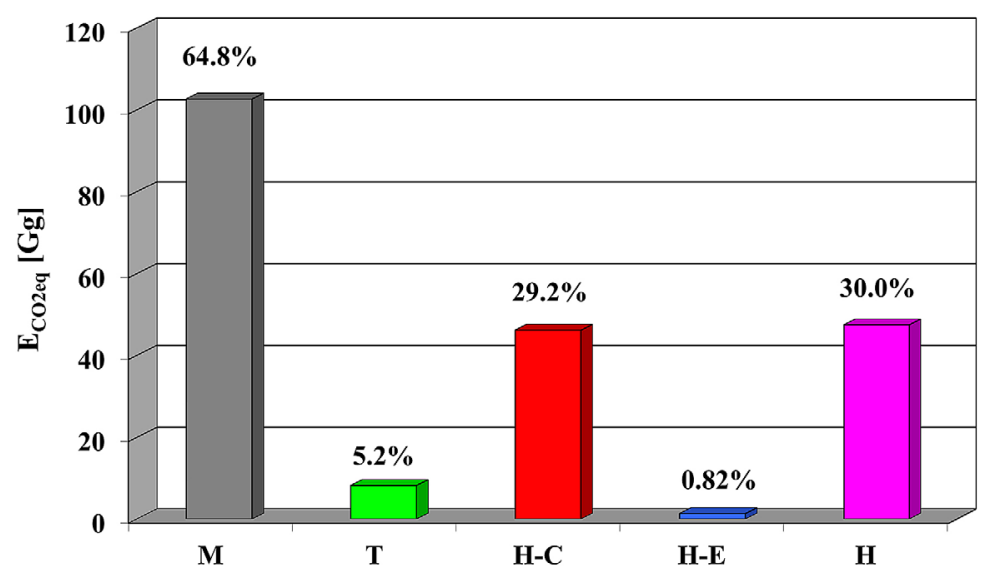

Figure 2. Equivalent carbon dioxide emission from the cumulative processes of useful energy generation in the heating plant: hard coal mining $-\mathrm{M}$, hard coal transport $-\mathrm{T}$, hard coal burning in the heating plant $-\mathrm{H}-\mathrm{C}$, electricity consumption in the heating plant $-\mathrm{H}-\mathrm{E}$ 


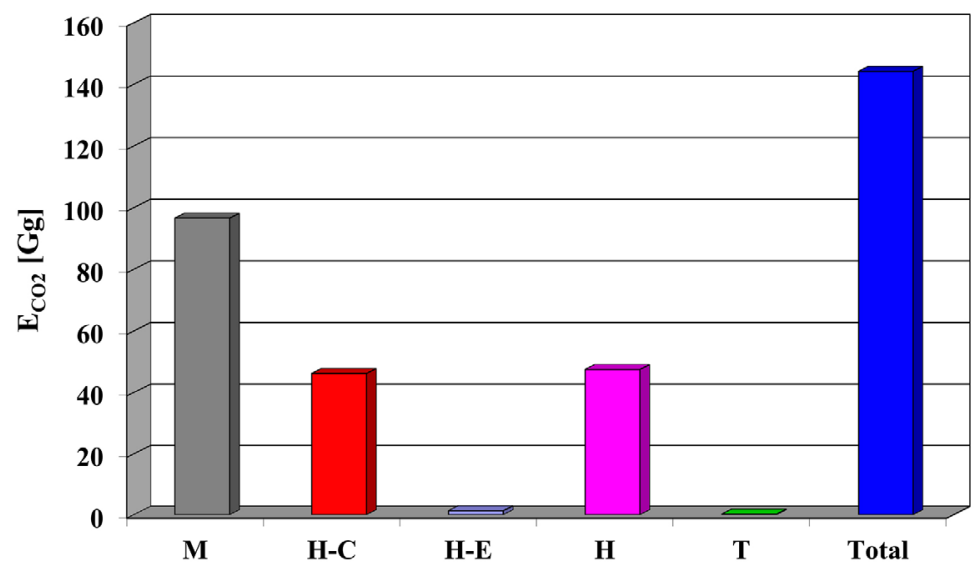

Figure 3. Carbon dioxide emission from the cumulative processes of useful energy generation in the heating plant: hard coal mining $-\mathrm{M}$, hard coal transport - $\mathrm{T}$, hard coal burning in the heating plant $-\mathrm{H}-\mathrm{C}$, electricity consumption in the heating plant $-\mathrm{H}-\mathrm{E}$

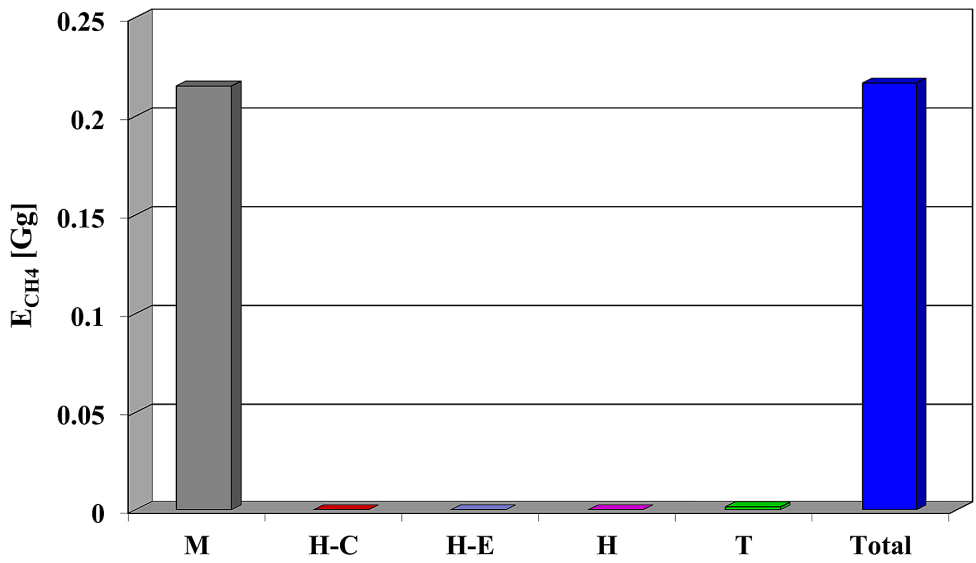

Figure 4. Methane emission from the cumulative processes of useful energy generation in the heating plant: hard coal mining $-\mathrm{M}$, hard coal transport $-\mathrm{T}$, hard coal burning in the heating plant $-\mathrm{H}-\mathrm{C}$, electricity consumption in the heating plant $-\mathrm{H}-\mathrm{E}$

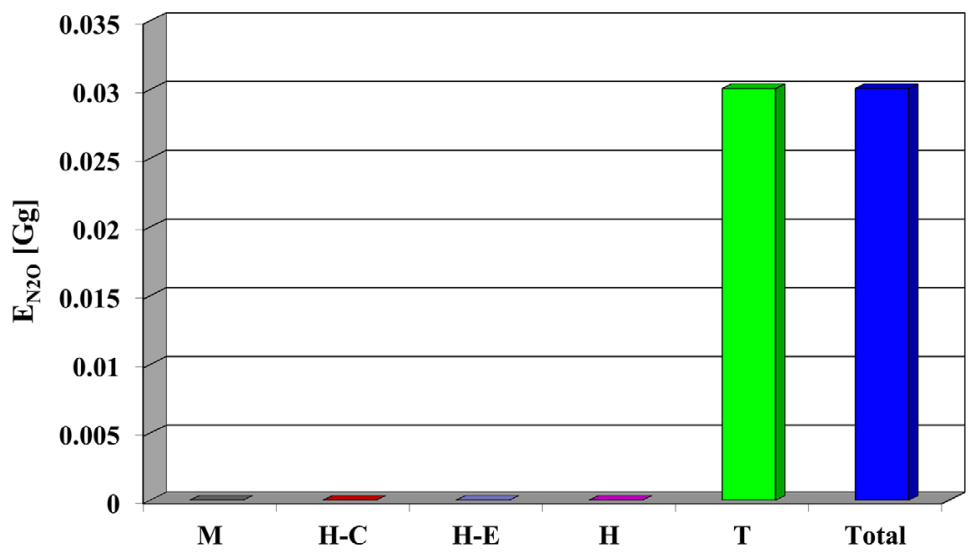

Figure 5. Nitrous oxide emission from the cumulative processes of useful energy generation in the heating plant: hard coal mining $-\mathrm{M}$, hard coal transport $-\mathrm{T}$, hard coal burning in the heating plant $-\mathrm{H}-\mathrm{C}$, electricity consumption in the heating plant $-\mathrm{H}-\mathrm{E}$ 


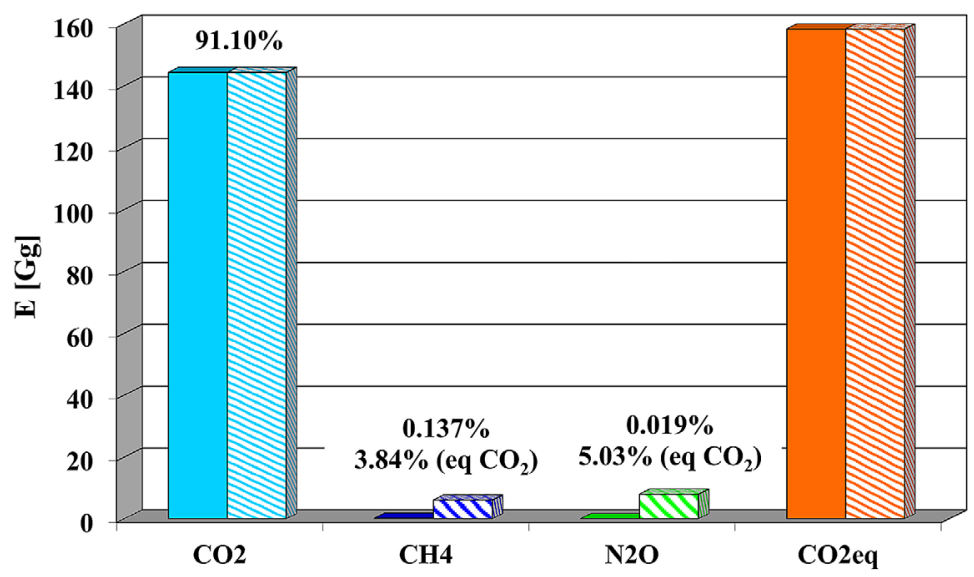

Figure 6. Greenhouse gas emissions in the process of useful energy generation in the heating plant and the relevant equivalent carbon dioxide emission

greenhouse gas emissions from the energy sector, the fossil carbon dioxide emission prevails (over $90 \%$ ), notwithstanding the relatively low potential of this gas for creating the greenhouse effect when compared to other greenhouse gases.

\section{CONCLUSIONS}

The results of the present carbon footprint study, carried out in the selected coal-fired heating plant, indicate that the dominant source of the greenhouse gas emissions is the hard coal mining process. The obtained results contradict with a common belief that burning fossil fuels is generally responsible for high greenhouse gas emissions from the energy sector. It appears that the dominant process in the energy sector is the energy-consuming mining of fossil fuels.

The issue of greenhouse gas emissions is difficult to resolve in the energy sectors of the countries with the economies traditionally based on fossil energy materials/carriers. The solution to this problem has been subject to sustainable development obligations, which equally emphasize the economic, social and ecological aspects. Replacing fossil energy carriers with renewable ones is not always the best solution, not only due to the burden of large investments, but also due to the relatively low power density of such carriers, e.g. wind energy or the energy from photovoltaic systems. The development of nuclear power systems seems to be a good solution. In the latter case, however, there is a risk of problems, which are not only of a financial nature (large capital expenditure), but also result from the social resistance to the nuclear technology.

\section{REFERENCES}

1. ADEME 2009. BP X30-323: Repository of Good Practices. French Agency for the Environment and Energy Management, Paris, France.

2. Aghahosseini A., Bogdanov D., Barbosa L.S.N.S., Breyer C. 2019. Analyzing the feasibility of powering the Americas with renewable energy and interregional grid interconnections by 2030 . Renewable and Sustainable Energy Reviews, 105, 187-205.

3. Agrawal K.K., Jain S., Jain A.K., Dahiya S. 2014. Assessment of greenhouse gas emissions from coal and natural gas thermal power plants using life cycle approach. International Journal of Environmental Science and Technology, 11, 1157-1164.

4. Atkins M.J., Walmsley T.G., Philipp M., Walmsley M.R.W., Neale J.R. 2017. Carbon emissions efficiency and economics of combined heat and power in New Zealand. Chemical Engineering Transactions, 61, 733-738.

5. BSI 2011. Publicly Available Specification (PAS 2050). Specification for the assessment of the life cycle greenhouse gas emissions of goods and services. British Standards Institute, London, United Kingdom. Available online: http://shop.bsigroup. com/upload/shop/download/pas/pas2050.pdf (accessed on 20 October 2020).

6. De Souza Grilo M.M., Chaves Fortes A.F., Gonzaga de Souza R.P., Mendes Silva J.A., Carvalho M. 2018. Carbon footprints for the supply of electricity to a heat pump: Solar energy vs. electric grid. Journal of Renewable and Sustainable Energy, 10, 023701.

7. Dias A.C., Arroja L. 2012. Comparison of methodologies for estimating the carbon footprint - case study of office paper. Journal of Cleaner Production, $24,30-35$.

8. EIB 2020. Project carbon footprint methodologies for the assessment of project GHG emissions and 
emission variations. Version 11.1. Available online: https://www.eib.org/attachments/strategies/eib project_carbon_footprint_methodologies_en.pdf. (accessed on 20 October 2020).

9. EMEP/EEA 2019. EMEP/EEA Air Pollutant Emission Inventory Guidebook. Publications Office of the European Union: Brussels, Belgium. Available online: https://www.eea.europa.eu/publications/ emep-eea-guidebook-2019 (accessed on 20 October 2020).

10. Gai Z-j., Zhao J-g., Zhang G. 2018. Typical calculation and analysis of carbon emissions in thermal power plants. IOP Conference Series: Earth and Environmental Science, 128, 012176.

11. Garcia R., Freire F. 2014. Carbon footprint of particleboard: A comparison between ISO/TS 14067, GHG Protocol, PAS 2050 and Climate Declaration. Journal of Cleaner Production, 66, 199-209.

12. Gonzalez-Salazar M.A., Kirsten T., Prchlik L. 2018. Review of the operational flexibility and emissions of gas- and coal-fired power plants in a future with growing renewables. Renewable and Sustainable Energy Reviews, 82, 1497-1513.

13. Houghton J.T., Ding Y., Griggs D.J., Noguer M., van der Linden P.J., Dai X., Maskell K., Johnson C.A. (eds.) 2001. Climate change 2001: the scientific basis. Contribution of Working Group I to the 3rd Assessment Report of the Intergovernmental Panel on Climate Change. Cambridge University Press, Cambridge. Available online: https://www.ipcc.ch/ site/assets/uploads/2018/07/WG1_TAR_FM.pdf (accessed on 20 October 2020).

14. INFRAS AG 2010. Handbuch für Emissionsfaktoren des Strassenverkehrs. Version 3.1.

15. IPCC 2006. 2006 IPCC Guidelines for National Greenhouse Gas Inventories. Available online: https:/www.ipcc-nggip.iges.or.jp/public/2006gl/ (accessed on 20 October 2020).

16. ISO 14040:2006. Environmental management Life cycle assessment - Principles and framework. International Organization for Standardization, Geneva, Switzerland.

17. ISO 14044:2006. Environmental management Life cycle assessment - Requirements and guidelines. International Organization for Standardization, Geneva, Switzerland.

18. ISO 14067:2018. Greenhouse gases - Carbon footprint of products - Requirements and guidelines for quantification. International Organization for Standardization, Geneva, Switzerland.

19. JRC 2011. Analysis of Existing Environmental Footprint Methodologies for Products and Organizations: Recommendations, Rationale, and Alignment. Deliverable 1 to the Administrative Arrangement between DG Environment and Joint Research Centre No. N 070307/2009/552517, including
Amendment No 1 from December 2010. European Commission, Joint Research Centre, Institute for Environment and Sustainability, Ispra, Italy. Available online: https://ec.europa.eu/environment/archives/eussd/pdf/Deliverable.pdf (accessed on 20 October 2020).

20. KOBiZE 2017. Calorific values (CV) and CO2 emission factors (EF) in 2015 to be reported under the European Union Emission Trading System for 2018. Available online: https://www.kobize.pl/ uploads/materialy/materialy_do_pobrania/monitorowanie_raportowanie_weryfikacja_emisji_w_eu ets/WO_i_WE_do_stosowania_w_SHE_2018.pdf (accessed on 20 October 2020) (in Polish).

21. KOBiZE 2019. CO2, SO2, NOx, CO and total particulate matter emission factors for electricity generation based on the information contained in the National Database on Emissions of Greenhouse Gases and Other Substances for 2018. Available online: https:/www.kobize.pl/uploads/materialy/ materialy_do_pobrania/wskazniki_emisyjnosci/ Wskazniki_emisyjnosci_grudzien_2019.pdf (accessed on 20 October 2020) (in Polish).

22. Myhre G., Shindell D., Bréon F.-M., Collins W., Fuglestvedt J., Huang J., Koch D., Lamarque J.-F., Lee D., Mendoza B., Nakajima T., Robock A., Stephens G., Takemura T., Zhang H. 2013. Anthropogenic and Natural Radiative Forcing. In Climate Change 2013: The Physical Science Basis. Contribution of Working Group I to the Fifth Assessment Report of the Intergovernmental Panel on Climate Change; Stocker T.F., Qin D., Plattner G.-K., Tignor M., Allen S.K., Boschung J., Nauels A., Xia Y., Bex V., Midgley P.M., Eds. Cambridge University Press: Cambridge, United Kingdom and New York, USA.

23. Pattara C., Russo C., Antrodicchia V., Cichelli A. 2016. Carbon footprint as an instrument for enhancing food quality: Overview of the wine, olive oil and cereals sectors. Journal of the Science of Food and Agriculture, 97(2), 396-410.

24. Peter C., Fiore A., Hagemann U., Nendel C., Xiloyannis C. 2016. Improving the accounting of field emissions in the carbon footprint of agricultural products: A comparison of default IPCC methods with readily available medium-effort modeling approaches. International Journal of Life Cycle Assessment, 21, 791-805.

25. Schmied M., Knörr W. 2012. Calculating GHG Emissions for Freight Forwarding and 22 - Logistics Services in Accordance with EN 16258. European Association for Forwarding, Transport, Logistics and Customs Services (CLECAT). Available online: https://www.clecat.org/media/CLECAT_Guide_ on_Calculating_GHG_emissions_for_freight_forwarding_and_logistics_services.pdf (accessed on 20 October 2020).

26. SMPO. EcoLeaf Environmental Labeling Program. 
Sustainable Management Promotion Organization. Available online: https://ecoleaf-label.jp/english (accessed on 20 October 2020).

27. Soode E., Weber-Blaschke G., Richter K. 2013. Comparison of product carbon footprint standards with a case study on poinsettia (euphorbia pulcherrima). International Journal of Life Cycle Assessment, 18(7), 1280-1290.

28. Statistics Poland 2018. Consumption of fuels and energy carriers in 2018. Available online: https:// stat.gov.pl/en/topics/environment-energy/energy/consumption-of-fuels-and-energy-carriersin-2018,8,13.html (accessed on 20 October 2020).

29. Wang S., Wang W., Yang H. 2018. Comparison of Product Carbon Footprint Protocols: Case Study on Medium-Density Fiberboard in China. International Journal of Environmental Research and Public
Health, 15(10), 2060.

30. Whittaker C., Mcmanus, M.C., Hammond G.P. 2011. Greenhouse gas reporting for biofuels: A comparison between the RED, RTFO and PAS 2050 methodologies. Energy Policy, 39(10), 5950-5960.

31. WRI/WBCSD 2006. Allocation of GHG emissions from a combined heat and power (CHP) plant guide to calculation worksheets (September 2006) v1.0. WRI/WBCSD GHG Protocol Initiative. Available online: https:/ghgprotocol.org/sites/default/files/ CHP_guidance_v1.0.pdf (accessed on 20 October 2020).

32. WRI/WBCSD 2011. Greenhouse Gas Protocol Product Standard. World Resources Institute/World Business Council for Sustainable Development. Available online: https://ghgprotocol.org/productstandard (accessed on 20 October 2020). 